\title{
Ruínas de mitos, sementes de sonhos: Ditos e provérbios em Guimarães Rosa e Luandino Vieira
}

Fabiana Buitor Carelli Marquezini

Universidade de São Paulo

RESUMO: NESTE ENSAIO, A AUTORA ANALISA PROVÉRBIOS E AFORISMOS PRESENTES EM GRANDE SERTÃO: VEREDAS, DE GUIMARÃES ROSA, E EM JOÃO VÊNCIO: OS SEUS AMORES E NÓS, OS DO MAKULUSU, DE LUANDINO VIEIRA, ENQUANTO FORMAS TIPICAMENTE ORAIS APROPRIADAS PELO GÊNERO ROMANCE, REVELANDO SUA FUNÇÃO ESTRUTURAL NOS TEXTOS E OS MODOS DE SUA APROPRIAÇÃO PELA ESCRITA.

ABSTRACT: IN THIS ARTICLE, THE AUTHOR ANALYZES PROVERBS AND APHORISMS WITHIN GUIMARÃES ROSA'S GRANDE SERTÃO: VEREDAS AND LUANDINO VIEIRA'S JOÃO VENNCIO: OS SEUS AMORES AND NÓS, OS DO MAKULUSU AS TYPICAL ORAL FORMS APPROPRIATED BY THE NOVEL AS A LITERARY GENRE, TRYING TO REVEAL THEIR STRUCTURAL FUNCTION WITHIN THE TEXTS AND THE MODES OF THIS WRITTEN APPROPRIATION.

PALAVRAS-CHAVE: GUIMARÃES ROSA - LUANDINO VIEIRA - ORALIDADE E LITERATURA - ROMANCE BRASILEIRO - ROMANCE ANGOLANO

KEY-WORDS: GUIMARÃES ROSA - LUANDINO VIEIRA - ORALITY AND LITERATURE BRAZILIAN NOVEL - ANGOLAN NOVEL 


\section{A lei e a letra}

$\mathrm{m}$ seu, livro sobre as relações entre oralidade e escrita, Walter Ong cita o provérbio como uma das formas típicas da cultura oral, já que, por meio do seu padrão rítmico e sintaxe balanceada ${ }^{1}$, e sem o auxílio do registro escrito, ele se torna conhecimento pronto para ser memorizado e resgatado sempre que preciso. Ong lembra ainda que, em culturas nas quais a oralidade predomina, mesmo as questões sociais são geralmente resolvidas por meio da aplicação dos provérbios, que constituem muitas vezes o corpo das leis nãoescritas de um determinado povo ou sociedade:

The law itself in oral cultures is enshrined in formulaic sayings, proverbs, which are not mere jurisprudential decorations, but themselves constitute the law. A judge in an oral culture is often called on to articulate sets of relevant proverbs out of which he can produce equitable decisions in the cases under formal litigation before him. (ONG, 1982: 35)

André Jolles, por sua vez, classifica os provérbios entre as chamadas "formas simples", acentuando que eles constituem a cristalização conceptual de uma experiência no interior de um universo específico e, como tal, são um saber de tipo indutivo, transmitido a posteriori. Como num dito de Riobaldo a respeito de atitudes consideradas "malucas" durante a vida ("Maluqueiras é o que não dá certo. Mas só é maluqueira depois que se sabe que não acertou!"; ROSA, 1967: 322), Jolles considera que, “[n]os provérbios, existe sempre uma tampa sobre o poço - mas que só é posta depois de a criança ter-se afogado" (JOLLES, 1976: 135).

Além disso, ao contrário de Ong, Jolles chama a atenção para uma possível distinção entre formas proverbiais próprias da cultura oral (que ele chama de "populares") e outras, especificamente literárias e criadas no contexto da escritura - embora não veja, entre elas, grandes diferenças do ponto de vista formal. Para ele, "o provérbio é uma locução" que "não é um conceito de base per

\footnotetext{
${ }^{1}$ No sentido de apresentar um tipo de estrutura paralelística típica das formas orais, como em "Quem com ferro fere com ferro será ferido", "Muito riso, pouco siso", etc.
} 
se, mas que deve ser reduzido a um conceito de base" (JOLLES, 1976: 130-1 e 132), e cuja estrutura (tipo de vocabulário, sintaxe, linha melódica, imagens utilizadas) ele procura brevemente analisar (JOLLES, 1976: 139-143).

A partir das duas perspectivas críticas citadas, é possível definir o provérbio como um saber originado na experiência e estruturado numa locução formalmente trabalhada, do ponto de vista do léxico, da sintaxe e do estilo, a qual funciona, nos contextos eminentemente orais de transmissão do conhecimento, como meio de armazenagem e de memorização desse saber, e também de ênfase. Nesta análise, considero não apenas os provérbios no sentido estrito, do ponto de vista formal (sentenças estruturadas mediante uso evidente de rimas, paralelismo sintático e semântico, etc.), mas também os ditos aforismáticos que, embora menos trabalhados formalmente, transmitam sinteticamente algum tipo de conhecimento ou experiência.

\section{Arqueologia do saber}

A leitura de Grande sertão: veredas mostra que Riobaldo é, decididamente, um narrador sentencioso. Num discurso que procura ser a formulação de perguntas essenciais a respeito do sentido da vida, do bem e do mal, do destino e dos limites da vontade humana e, ao mesmo tempo, uma articulação das respostas, os provérbios ou aforismos proferidos pelo narrador ou abrem a narrativa de certos episódios do romance, indicando o sentido que esses episódios devem ter em sua argumentação, ou os concluem, conferindo-lhes uma significação mais geral.

No início do romance, por exemplo, a narrativa do caso do Aleixo e de seus filhos cegos é introduzida pelas seguintes afirmações de Riobaldo:

Que o que gasta, vai gastando o diabo de dentro da gente, aos pouquinhos, é o razoável sofrer. E alegria de amor - compadre meu Quelemém diz. Família. Deveras? É, e não é. O senhor ache e não ache. Tudo é e não é... (ROSA, 1967: 12),

nas quais tanto a sentença inicial ("Que o que gasta, vai gastando [...] é o razoável sofrer") quanto a final (“Tudo é e não é”) podem ser consideradas ditos aforismáticos, e conferem um sentido à história que se contará a seguir. 
Logo depois do episódio da Guararavacã do Guaicuí e da descoberta do amor por Diadorim, porém, durante a primeira perseguição aos “judas” após terem tomado ciência do assassinato de Joca Ramiro, e como que a concluir, sentenciosamente, a narração de suas angústias acerca de não conseguir resolver imediatamente sua relação com o "amigo", Riobaldo comenta: "Para ódio e amor que dói, amanhã não é consôlo” (ROSA, 1967: 231)².

Assim, tanto no sentido de introduzirem episódios quanto no de concluílos, os ditos proverbiais, no texto de Rosa, parecem corresponder à visão de André Jolles de que eles sejam cristalizações de experiências já vividas. Mesmo as sentenças aforismáticas que abrem episódios mostram que as conclusões sobre o significado dos fatos narrados, tanto os acontecidos com Riobaldo quanto os recontados por ele, são justamente a tese que o narrador parece querer confirmar com sua narrativa subseqüente. Visto sob esse prisma, o romance parece corresponder a uma longa prova retórica a respeito da inexistência do diabo, assim como retóricas seriam até mesmo as perguntas, aparentemente inocentes e ineptas, que Riobaldo faz a seu letrado interlocutor, já que as respostas parecem estar todas dadas:

Mas tem um porém: pergunto: o senhor acredita, acha fio de verdade nessa parlanda, de com o demônio se poder tratar pacto? Não, não é não? Sei que não há. Falava das favas. Mas gosto de tôda boa confirmação. (ROSA, 1967: 22)

Sendo assim, sabendo mais do que declara saber e cristalizando essa sabedoria em sentenças é que Riobaldo vai tecendo seu texto a respeito dos assuntos que mais o interessam. O levantamento desses ditos aforismáticos mostra que eles versam sobre grandes temas, como a vida e a morte, o homem e sua natureza, o sertão, Deus e o diabo, o destino, o medo e a coragem, o bem e o mal, a guerra, a jagunçagem, o amor e, de modo muito especial, o próprio saber viver. A seguir, cito alguns exemplos.

A respeito da guerra e dos jagunços, vistos respectivamente como expressão do mal e aqueles que para ele trabalham, Riobaldo afirma: "Vi: o que

\footnotetext{
${ }^{2}$ Nesta e em outras citações de Grande sertão: veredas, optei por manter a grafia original da edição consultada.
} 
guerreia é o bicho, não é o homem” (ROSA, 1967: 417); "Jagunço amolece, quando não padece” (ROSA, 1967: 223); "Quem de si de ser jagunço se entrete, já é por alguma competência entrante do demônio, será não?” (ROSA, 1967: 11).

Sobre a natureza humana, limitada e cheia de imperfeições, mas que em certos e raros momentos se supera, as afirmações do narrador são como as seguintes: "Bananeira dá em vento de todo lado. Homem? É coisa que treme” (ROSA, 1967: 118); "Criatura gente é não e questão, corda de três tentos, três tranços" (ROSA, 1967: 32); "O mais importante e bonito, do mundo, é isto: que as pessoas não estão sempre iguais, ainda não foram terminadas - mas que elas vão sempre mudando. Afinam ou desafinam" (ROSA, 1967: 20-1).

Sobre a coragem, qualidade essencial no universo do sertão e, já que “o sertão é o mundo", da própria natureza humana, de acordo com os valores de Riobaldo, há declarações como as seguintes: "Que: coragem - é o que o coração bate; se não, bate falso. Travessia - do sertão - a tôda travessia" (ROSA, 1967: 379); "Vau do mundo é a coragem..." (ROSA, 1967: 232).

Sobre o amor e suas (in)certezas: "Ah, a flôr do amor tem muitos nomes" (ROSA, 1967: 146); "Amor é assim - o rato que sai dum buraquinho: é um ratazão, é um tigre leão!” (ROSA, 1967: 323); "Só se pode viver perto de outro, e conhecer outra pessoa, sem perigo de ódio, se a gente tem amor. Qualquer amor já é um pouquinho de saúde, um descanso na loucura. Deus é que me sabe" (ROSA, 1967: 236).

Sobre Deus, que é o saber escondido por trás da aparente desordem do mundo, que tudo vê e tudo vence:

O diabo, é às brutas; mas Deus é traiçoeiro! Ah, uma beleza de traiçoeiro - dá gôsto! A fôrça dele, quando quer - môço! - me dá o mêdo pavor! Deus vem vindo: ninguém não vê. Ele faz é na lei do mansinho - assim é o milagre. E Deus ataca bonito, se divertindo, se economiza. (ROSA, 1967: 21)

Sobre a vida, tão "perigosa", porque vivida às cegas: "Deus vem, guia a gente por uma légua, depois larga. Então, tudo resta pior do que era antes. Esta vida é de cabeça-para-baixo, ninguém pode medir suas pêrdas e colheitas" (ROSA, 1967: 112). 
Por fim, sobre o saber viver, tão fundamental para não se perder a vida, e tão raro, "no meio da travessia", declara o narrador: "As coisas assim a gente mesmo não pega nem abarca. Cabem é no brilho da noite. Aragem do sagrado. Absolutas estrêlas!" (ROSA, 1967: 319).

A leitura conjunta desses e de outros aforismos de Riobaldo dá ao leitor uma idéia mais ou menos abrangente sobre as conclusões a que esse exjagunço e fazendeiro "de range-rede" chegou a respeito da vida e das perguntas que o atormentaram ao longo da existência. Assim, curiosamente, a narrativa, estruturada como um conjunto de perguntas ao interlocutor letrado, é também, ao menos sob o ponto de vista dos ditos aforismáticos que a constituem, um entrançado de respostas quase sempre categóricas sobre as questões fundamentais de Riobaldo Tatarana. Sob esse prisma, o texto, ao mesmo tempo em que flerta com o saber culto do interlocutor, adulando-o no plano mais aparente ("O senhor não acha? Me declare, franco, peço. Ah, lhe agradeço. Se vê que o senhor sabe muito, em idéia firme, além de ter carta de doutor"; ROSA, 1967: 22), impõe a ele, de maneira quase totalitária (ainda que precária...), o saber do narrador, baseado na dimensão, para este bastante concreta, da experiência pessoal e também daquela que lhe fora transmitida oralmente pela cultura do sertão. É como se Riobaldo, apesar de insinuá-lo, não quisesse exatamente se apossar do saber do interlocutor, mas, sim, conseguir dele, que é, no texto, o representante das instâncias mais cultas e letradas da sociedade, um aval para seu próprio saber, fundamentado na vivência e na tradição.

É nesse sentido que se pode citar aqui uma afirmação de João Adolfo Hansen segundo a qual, em Grande sertão: veredas, "falam as linguagens do mato" (HANSEN, 2000: 191). A fala ininterrupta (e aforismática) de Riobaldo constitui, sobre esse interlocutor letrado, que compulsoriamente se cala, o exercício de um poder:

[No Grande sertão: veredas,] A competência se reflete no direito de impor a recepção: os que falam fazem de si e de seu discurso uma imagem pela qual se representam os que ouvem como dignos de escutar, enquanto os que ouvem se figuram [sic] os que falam como dignos de falar, pois o poder da palavra é sempre o de uma palavra de poder [...]. (HANSEN, 2000: 62) 
Nesse sentido, também é possível afirmar que, no discurso dialeticamente tenso que é o Grande sertão, sempre vertido sobre a relação entre as práticas lingüísticas cultas e as de extração popular ou regional, sobre como uma se transforma em outra e vice-versa, é na presença dos ditos aforismáticos da fala de Riobaldo que se percebe um dos traços mais evidentes da "manutenção", entre aspas porque já convertida em discurso escrito, da oralidade no romance, não apenas do ponto de vista formal, mas também do ideológico.

Curiosamente, porém, e pelas próprias características do livro de Rosa, essa "manutenção" da oralidade é, também, sua superação, já que ela é feita por meio da forma romance, gênero eminentemente escrito e, tal como desenvolvido a partir do século XVIII, ligado às formas impressas de transmissão da experiência.

Em um artigo em que analisa especificamente as "estórias" de Tutaméia, Luiz Costa Lima, citando Walter Benjamin, relaciona a presença insistente de provérbios e aforismos na narrativa de Guimarães Rosa justamente ao vínculo que algumas obras do escritor mineiro mantêm com a oralidade e com a narrativa comunitária:

De que então seria o provérbio fragmento sobrevivo? Desde logo, do tempo da oralidade e da narração. O provérbio é índice de um tempo, abolido com as condições que favoreceram o advento do romance, pois o lugar de nascimento do romance é o indivíduo solitário, que não pode mais traduzir sob forma exemplar o que nele é mais essencial, pois não mais recebe conselhos e já não os sabe dar' (Benjamin: 1936, p. 297). [...] Conhecimento fragmentado — talvez mesmo ruína de mitos —, o provérbio encarna a parte duma cosmovisão, que, entretanto, não saberíamos reconstituir, pois, ao contrário do que sucede com a narração mítica, sua propagação nos impede de conhecer o contexto primitivo de que derivou. (LIMA, 1974: 16; grifo do autor)

Costa Lima postula ainda que, no caso das narrativas curtas de Tutaméia, "o provérbio funciona como elo que reúne o contingente, o destino individual, e o território das perguntas irrespondíveis” (LIMA, 1974: 20), que seria aquele do mito, por meio do que se daria, então, o processo inverso ao que se observa no vetor do Grande sertão: veredas que caminha da tradição à modernidade: a reconstrução (relativa, porque escrita) de um discurso de 
caráter mítico, portanto mais próximo da narrativa comunitária, por meio de uma espécie de "colagem" dos seus cacos, que seriam os provérbios.

No Grande sertão, a meu ver, os ditos aforismáticos de Riobaldo, apesar de constituírem uma afirmação do poder da sabedoria tradicional diante da força destruidora da letra, emudecida e, de certa forma, emasculada no interlocutor que nada fala, são uma espécie de "canto do cisne", após o qual todo esse universo sobre o qual discursa o narrador - o sertão e seus saberes - pulveriza-se irremediavelmente. Isso porque, como mostrou Davi Arrigucci Jr., o Grande sertão: veredas, no plano da situação discursiva que une (e separa) narrador e interlocutor, é a narrativa da experiência individual de Riobaldo e, como tal, um romance de aprendizagem ou de formação, ainda que seu ponto de partida seja uma trama romanesca de "fundo arcaico":

O fundo arcaico - de cujo oco mais profundo no sertão, reino de uma mitologia ctônica, parece ter saído o Hermógenes - é também o da cercania do mito. Dali brota a aventura dos heróis romanescos, dos grandes chefes jagunços: narrativa propriamente épica, que acaba por se definir como história de uma busca de vingança, incitada e tensionada pela paixão amorosa [...].

Mas, sobre essa estória romanesca, em que age o jagunço Riobaldo - o Cerzidor, o Tatarana, o Urutu-Branco -, Riobaldo-Narrador constrói a tentativa de esclarecimento do sentido de sua vida, o relato de sua experiência individual, singularizada a partir de um encontro único e enigmático com o Menino, que será Diadorim - marco de sua travessia pessoal e ponto de interrogação que lhe coloca questões que não pode responder.

Ou seja, misturada à primeira, surge o romance de aprendizagem ou de formação, forma literária que a burguesia do Ocidente transformou, com o advento da Era Moderna, num dos principais instrumentos do seu espírito, debruçado sobre o sentido da experiência individual. (ARRIGUCCI JR., 1994: 17; grifo do autor)

\section{Enquanto isso, do outro lado do Atlântico...}

João Vêncio: os seus amores, misto de novela e romance criado por José Luandino Vieira na prisão, em 1968, é uma espécie de Grande sertão: veredas do escritor angolano. Nele, a situação discursiva é praticamente idêntica à da obra de Rosa: 
um mulato de pouco estudo, Juvêncio Plínio do Amaral, preso por tentar assassinar a esposa que o traíra com um branco, "conversa", no cárcere, com um intelectual também preso, buscando respostas para suas questões fundamentais. Como em Grande sertão, o interlocutor letrado nunca tem voz no texto, e o que lemos é o longo monólogo de Juvêncio, ou João Vêncio, o apelido usado por ele.

Nessa obra, percebe-se que o narrador criado por Luandino Vieira vai adotando uma postura discursiva sentenciosa semelhante à do Riobaldo de Guimarães Rosa, a ponto de, segundo indica o texto, ser chamado de "sentencista" (VIEIRA, 1987: 14). Diante de seu interlocutor letrado, de seu "muadié", João Vêncio desfia, ou "dá o fio", como diz, a aforismos como os citados a seguir, a respeito de assuntos diversos.

Sobre sua capacidade de se articular segundo os padrões do discurso jurídico, afirma: "O quituta-tuje é da féz que faz o brilho que traz" (VIEIRA, 1987: $14)^{3}$; sobre a falta de capacidade discursiva dos juristas jovens, comenta: "Língua deles é de açúcar-branco, adoça mas derrete” (VIEIRA, 1987: 14); sobre o destino do homem, sua sorte ou "miondona" (que, acredita João Vêncio, já nasce com cada um), diz: "No ovo já está o pintinho, cada cor é o ar com is" (VIEIRA, 1987: 18); sobre aspectos negativos da natureza humana, como a calúnia ou a inveja, sentencia: "Quem sobe, sombra dele é quimbriquito de muita gente; mas escurece..." (VIEIRA, 1987: 59), e "Calúnia é rabo de sardão - cortado ainda, vive... Recresce!” (VIEIRA, 1987: 60); sobre a amizade e o amor, declara: "Amizade é chuva-de-caju... boa é na seca, boa é na esperança de março de chuva. Amor..." (VIEIRA, 1987: 25), e "O amor é assim, muadié, me diga então: desforra de qualquera coisa?” (ibid.).

Ao lado desses exemplos, que, como em Grande sertão: veredas, parecem significar a recriação de fragmentos típicos da tradição oral na narrativa, destacam-se, em João Vêncio, dois outros tipos de procedimento discursivo em relação aos ditos sentenciosos.

O primeiro é que, além de citar ou elaborar aforismos em português, o narrador também o faz usando o quimbundo. Por meio da sentença "A-mubeta kua mundele, kufundilé kua mundele" (VIEIRA, 1987: 14), que, se-

\footnotetext{
${ }^{3}$ Segundo o glossário do livro, "quituta-tuje", do quimbundo kituta tuji, significa "escaravelho".
} 
gundo o glossário do texto, quer dizer "Se um branco te bater, não te queixes a outro branco" (VIEIRA, 1987: 93), Vêncio faz uma crítica à Justiça que o prendera e o estava processando por tentativa de homicídio. Já em "Tambi ia mon'a mukuenu, b’o telu dia mujinha" (VIEIRA, 1987: 46)4 rindo justamente a palavras proferidas durante certos rituais fúnebres tradicionais em que histórias são contadas, adivinhas e adágios são propostos, para depois se fazer uma festa em honra do morto. O aparecimento de ditos proverbiais em quimbundo no texto é, assim, referência explícita, inclusive pelo uso da língua, a uma Justiça não-branca e a tradições ligadas à oralidade que, como afirma o próprio João Vêncio, parecem estar morrendo: "Minhas festanças, dores dos outros - os óbitos. Cair num bom óbito, bem chorado, choro de velhotas, as meninas de agora não sabem honrar defunto com suas lágrimas, que é a indecência" (VIEIRA, 1987: 46).

Esse processo transformador e, por que não dizer, reformador de ditos e provérbios está ligado ao forte traço paródico desse livro de Luandino e também, ao que parece, à intenção do narrador João Vêncio de fazer com que os conhecimentos tradicionais de que é portador ganhem, de algum modo, por meio da contra-ação discursiva do muadié, sempre calado, mas de quem Vêncio diz esperar ajuda na estruturação de sua defesa perante os tribunais, um status social e político mais elevado, a ponto de melhor servirem a seus argumentos de defesa perante o tribunal branco.

Assim, em certos momentos do texto, o narrador cita provérbios conhecidos da tradição portuguesa e também cristã, como em "cedo erguer faz crescer” (VIEIRA, 1987: 31), “quem come bem pensa bem” (VIEIRA, 1987: 42), "morre o homem fica a fama" (VIEIRA, 1987: 46), "ganhar o mundo, perder a alma" (VIEIRA, 1987: 74), ou os vai parodicamente modificando, como em "o senhoro, ngana, cala mas não consente" (VIEIRA, 1987: 40), "meu pai deu-lhe a mão, ele pegou o pé” (VIEIRA, 1987: 58), "mais-velho, mais siso, menos riso" (VIEIRA, 1987: 85), até as colocações de que "quem pergunta desajunta", mas "[e]u sempre pergunto mesmo quando sei - posso estar errando..." (VIEIRA, 1987: 74) e, de modo bem claro, explicitando seu

\footnotetext{
4 “O óbito do filho alheio é lugar para fiar algodão" (VIEIRA, 1987: 105).
} 
procedimento, "pela lei, vem o pecado - eu invirto as sentenças de meu sô padre" (VIEIRA, 1987: 72; grifo meu).

Dessa forma, o que João Vêncio vai fazendo em sua narrativa é uma adaptação muitas vezes paródica de um saber veiculado sob uma forma tradicional, para que ele possa melhor servir ao propósito de provar sua inocência ou, pelo menos, justificar o crime que lhe fora imputado. Em seu discurso, a recuperação de traços da oralidade parece ter-se tornado necessária, a fim de que também fosse recuperada a ética que essa oralidade envolvia, na qual valores como a honra ainda eram tão relevantes a ponto de justificar a "tentativa de homicídio frustrado" do prisioneiro e garantir a sua libertação. Observe-se que, do ponto de vista do gênero, João Vêncio, os seus amores é um romance com fortes traços retóricos, e, como tal, apesar de a história contada pelo mulato estar sendo registrada por escrito pelo muadié, conforme explicita o texto, e de o livro ser, em si, uma obra escrita, essa narrativa guarda vínculos estreitos com a oralidade, já que o gênero retórico é, por excelência, oral.

\section{"Verdes amores, nunca mais"}

Se em João Vêncio, os seus amores já é possível distinguir ditos aforismáticos ligados a diferentes tradições culturais - a cultura autóctone, a portuguesa, a cristã-católica, etc. -, em Nós, os do Makulusu, romance de Luandino escrito em 1967 e em que certos ditos sentenciosos também reverberam, tal distinção se faz ainda mais evidente e relevante. Na narrativa profundamente fragmentada que é esse romance, o fluxo de consciência do narrador Mais-Velho é freqüentemente cortado por falas estranhas à sua e que ele vai incorporando. A voz do irmão Maninho, por exemplo, é tão preponderante em alguns momentos do texto que, neles, o alferes morto quase chega a assumir o papel de narrador, "usurpando-o" do irmãos.

\footnotetext{
${ }^{5}$ V., por exemplo, os longos trechos da fala de Maninho às páginas 26-29 da edição citada de Nós, os do Makulusu. A radicalização desse procedimento de incorporação de várias vozes que se tornam vários narradores no romance pode ser mais explicitamente verificada em Mayombe, de Pepetela, outro importante escritor angolano, publicado no Brasil pela Editora Ática, em 1982.
} 
É importante observar, no entanto, que o que se encontra em Nós, os do Makulusu não são exatamente provérbios, já que os ditos sentenciosos lidos nesse livro são mais opiniões particulares dos personagens a respeito das questões fundamentais dessa narrativa que ganham caráter geral do que declarações de natureza comunitária. Nesse romance, que é a história da formação de uma consciência política e, portanto, também pode ser considerado o romance de aprendizagem de Mais-Velho, esses "saberes", pessoais e precários, ecoam na memória do narrador. Aos poucos, ele os vai amadurecendo e transformando numa sabedoria propriamente sua e, assim, vai modificando o passado pela experiência, já que "nestes caminhos velhos [do Makulusu] não sai estrada nenhuma" (VIEIRA, 1985: 25) e que "ser é passado logo na hora que és" (VIEIRA, 1985: 80), como ele mesmo declara.

Dessa forma, os ditos sentenciosos do pai, imbuídos dos preconceitos de raça colonialistas, assim como as crenças simples e religiosas da mãe, afloram e são imediatamente negados, relativizados, num forte movimento dialógico e dialético de superação e de criação do novo:

Como é então, pai, tua sabedoria de colono?

- Quem com mulata casou e água do Bengo bebeu, nunca mais s'há de lembrar da terra onde nasceu! Ouviste, rapaz?

Ouvi pai, mas não é isso, nunca dormi com mulatas, tu não sabes.

- Se queres estragar a vida, arranja um carro velho, uma máquina fotográfica ou uma amante mulata!...

Rute vai ser tua nora póstuma, esses avisos não adiantam, velhote [...]. (VIEIRA, 1985: 73)

[...] fazer bem sem olhar quem, tu vives de frases feitas no teu bom senso de camponesa que és ainda e esse bom senso é muito perigoso. Fazer o bem sem olhar a quem é diminuir, é insultar - primeiro é preciso que reconheças esse a quem como alguém que não quer o teu bem, quer outro bem, e então, sim!: faze o bem e não olhes a quem, ama o próximo como a ti mesmo, assim como fizeres assim acharás, não o saiba a esquerda o que a direita faz, então sim, isso será bom e justo [...]. (VIEIRA, 1985: 51) 
As falas de certos personagens da infância e juventude são também objeto de referência e, por vezes, de desconstrução por Mais-Velho, como as palavras pretensamente politizadas do operário Brito, "o olho de água é que explica o rio" (VIEIRA, 1985: 80), com as quais esse personagem, que se afirma operário, procura explicar a "luta de classes" como origem do preconceito racial no país, e que vão se transformando, ao longo da narrativa, em "No olho d'água é que está o rio" (ibid.), "no olho d'água é que começa o rio" (ibid.), até explodirem no desabafo do narrador:

O problema é outro, meu velho que bebes gins-fistes e comes, gosmeiro, as peles queimadas e mulatas destas brancas todas que, noutros sítios do globo, iam olhar, banzas, o cartaz apontado pelo dedo ariano: 'No coloured admitted', ou se não fosse mais bíblico: 'Dogs and negroes out' etcétera, edcetra, tu é que escreveste os dísticos, sabes bem melhor que eu, porra! e que tu não ias aceitar sentadas ao teu lado, mesmo na paragem do maximbombo só. (VIEIRA, 1985: 81)

Ou as falas do tão amado Maninho, que critica o irmão Mais-Velho por suas posições moderadas e intelectuais, seu medo, sua prevenção em dormir com mulatas e negras: "A certeza, Mais-Velho, não nasce feita: tem-se fazendo-lhe, enquanto se faz, apenas" (VIEIRA, 1985: 139); "A dignidade, Mais-Velho, se mede no igual para igual" (VIEIRA, 1985: 33); "As mulheres quando amam verdadeiramente são os seres mais puros e revolucionários, Mais-Velho" (VIEIRA, 1985: 31). A longa crítica (lembrada ou imaginada?) de Maninho a Mais-Velho, tão contundente, termina com uma frase que é também um parágrafo, sucinta e direta, resposta do último ao primeiro, e que de certa forma o nega - afinal, com todas as suas opiniões, e devido a elas, Maninho morrera: "Só porque tens razão, também tenho" (VIEIRA, 1985: 29).

Por fim, e a partir de tudo isso, Mais-Velho vai construindo suas próprias e provisórias certezas, que também expressa por meio de declarações sentenciosas. Sobre a coragem: "A coragem é isto: meter o pássaro do medo na capanga" (VIEIRA, 1985: 126). Sobre o amor: "O amor não é uma coisa, é uma relação" (VIEIRA, 1985: 120); “O amor não é a coisa: é a doação” (VIEIRA, 1985: 130); "O amor não é um fruto; teia d'aranha de nervuras de folha, será assim?” (VIEIRA, 1985: 94). Sobre a cor da pele e a escravidão: "A pele não é o homem, a carne não é o homem - 'a mão é o cérebro!' não é, Coco - o homem é 
uma secreção de milhões de células nervosas que não nasce feito e nunca que se faz totalmente, nascendo-se cada dia" (VIEIRA, 1985: 82). Sobre a vida: "Vida é concreto, resto é morte" (VIEIRA, 1985: 83).

Mais do que provérbios ou aforismos, as declarações sentenciosas parecem funcionar, em Nós, os do Makulusu, como clichês (colonialistas, religiosos, revolucionários, éticos, etc.) que vão sendo desconstruídos e reconstruídos pelo discurso em bases diferentes, para depois serem negados e superados e, assim, o novo sobrepondo-se ao velho indefinidamente, é que o futuro no texto se faz e se fará. Não se identifica, nessas afirmações dos personagens, nem mesmo nas de Mais-Velho, o "fundo arcaico" de que fala Davi Arrigucci Jr. a respeito de algumas formas narrativas elementares que compõem o Grande sertão: veredas, nem se pode percebê-las como "ruína[s] de mitos", na expressão de Luiz Costa Lima, já que elas parecem ser, isso sim, fragmentos de discursos historicamente marcados, os quais, porque produzidos no tempo, são, também pelo tempo, desfeitos e superados.

Não há nessas sentenças, além disso, o traço de oralidade que temos observado até aqui nas demais narrativas, ao menos não no ponto de vista de elas serem vestígios ou tentativas de reconstituição de uma cultura predominantemente oral, à exceção de alguns dos provérbios proferidos pelo velho Paulo ou pela mãe do narrador. Em Nós, os do Makulusu, a narrativa trata, isto sim, de personagens cujas trajetórias são profundamente marcadas pela letra, e grande parte dos "saberes" que eles proferem são de origem livresca, inclusive a moral evangélica da mãe, que vem do Novo Testamento ("ama o próximo como a ti mesmo", "não o saiba a esquerda o que a direita faz"), as teorias do operário Brito (que, segundo Mais-Velho, só possuía um livro, Os dez dias que abalaram o mundo, de John Reed; VIEIRA, 1985: 81) ou mesmo a fala rebelde de Maninho, influenciada, entre outras, por sua leitura de For whom the bell tolls, de Ernest Hemingway (VIEIRA, 1985: 25 e 40-1).

Além disso, há que se pensar que provérbios ou aforismos, mesmo quando sobrevivem como formas eminentemente orais em culturas predominantemente letradas, não são, em geral, objeto de questionamento, mas se mantêm como formas socialmente aceitas ou caem em completo desuso, ao contrário do que se percebe acontecer com os ditos sentenciosos de Nós, os do Makulusu.

Esses fatores fazem acreditar, portanto, que as frases aforismáticas que essa narrativa apresenta não estejam vinculadas a formas sociais ou culturais da 
oralidade, mas pessoais - as vozes da infância e da adolescência de Mais-Velho -, sendo elas, assim, mais um traço do romance nesse livro admirável, naquilo que caracteriza esse gênero literário, nas palavras de Georg Lukács, como

a epopéia de um tempo em que a totalidade extensiva da vida não é já dada de maneira imediata, de um tempo para o qual a imanência de sentido à vida se tornou problema mas que, apesar de tudo, não cessou de aspirar à totalidade. (LUKÁCS, s. d.: 55)

A busca de um sentido para a vida e a aspiração (ainda que, e porque precária) à totalidade me parecem, de modo bastante contundente, características da trajetória e da narrativa de Mais-Velho, marcadas pela perda da noção do coletivo e pela solidão.

\section{"Para onde fores, irei"}

A epígrafe que abre o romance Nós, os do Makulusu, retirada de um conto tradicional angolano, diz, em quimbundo:

“...mukonda ku tuatundu kiá, kî tutena

kumona-ku dingi kima. O kima, tu-ki-

sanga, kiala tuala mu ia."

O texto, cuja tradução aproximada é “...de onde viemos, nada há para ver. O que procuramos está lá, para onde vamos”, conclui a última das histórias do volume Contos populares de Angola, antologia de narrativas da tradição oral em quimbundo compiladas no século XIX pelo etnólogo Héli Chatelain. Nessa história, intitulada "Kututunda ni kutuia", ou, em português, "O passado e o futuro", dois personagens, De onde venho e Para onde vou, apresentam-se diante de um juiz para saber qual dos dois tem mais razão. A resposta do juiz é que corresponde à citação de Luandino Vieira em seu livro: "De onde viemos já nada se pode obter e, pelo contrário, o que se puder encontrar está lá para onde vou” (CHATELAIN, 1964). 
Pensar nos traços da cultura oral presentes nas obras analisadas aqui, entre os quais os provérbios e aforismos, é pensar também em mudança e destruição. Como meteoros cruzando o céu do texto, eles brilham e morrem, inseridos num contexto escrito que definitivamente os transforma em algo novo. "De onde viemos", assim, mostra-se para ser visto; mas o novo, o "para onde vou", como na história citada por Luandino, este, sim, prevalece.

As três obras lidas aqui são, cada uma a seu modo, vetores em direção ao futuro, embora em Grande sertão: veredas possa ser percebida certa nostalgia de um passado sertanejo pulverizado pelo progresso, de um saber que, afinal, faísca e sucumbe diante da letra:

Mas, o senhor sério tenciona devassar a raso êste mar de territórios, para sortimento de conferir o que existe? Tem seus motivos. Agora - digo por mim - o senhor vem, veio tarde. Tempos foram, os costumes demudaram. Quase que, de legítimo leal, pouco sobra, nem não sobra mais nada. (ROSA, 1967: 23)

Em Luandino, por sua vez, esse futuro não é somente desejado, mas também construído por meio do discurso. E os traços de oralidade presentes em suas narrativas funcionam, não como cacos de um passado irremediavelmente perdido, mas como sementes de um porvir que se constrói no presente. Afinal, na África e na Angola que se fazem a cada dia, "vida é concreto, o resto é morte".

\section{Referências Bibliográficas}

ARRIGUCCI JR., Davi. O mundo misturado: romance e experiência em Guimarães Rosa. In: Novos Estudos. São Paulo: CEBRAP, n. 40, p. 7-29, nov. 1994.

CHATELAIN, Héli. Contos populares de Angola. Tradução de M. Garcia da Silva. Lisboa: Agência Central do Ultramar, 1964.

HANSEN, João Adolfo. OO: a ficção da literatura em Grande sertão: veredas. São Paulo: Hedra, 2000.

JOLLES, André. Formas simples: legenda, saga, mito, adivinha, ditado, caso memorável, conto, chiste. São Paulo: Cultrix, 1976.

LIMA, Luiz Costa. Mito e provérbio em Guimarães Rosa. In: Colóquio-Letras. Lisboa, n. 17, jan. 1974. 
LUKÁCS, Georg. A teoria do romance. Lisboa: Presença, s. d.

ONG, Walter J. Orality and literacy: the technologizing of the world. London/New York: Methuen, 1982.

ROSA, João Guimarães. Grande sertão: veredas. 5. ed. Rio de Janeiro: José Olympio, 1967.

VIEIRA, José Luandino. João Vêncio: os seus amores. 2. ed. Lisboa: Edições 70, 1987.

VIEIRA, José Luandino. Nós, os do Makulusu. 4. ed. Lisboa: Edições 70, 1985. 
